\title{
INTERVENÇÕES URBANAS PERPASSADAS POR BIOLOGIAS
}

\author{
URBAN INTERVENTIONS PERMEATED BY BIOLOGY
}

INTERVENCIONES URBANAS IMPREGNADAS DE BIOLOGÍAS

Daniela Franco Carvalho ${ }^{1}$

\begin{abstract}
Resumo
Esse texto traz provocações a partir do registro fotográfico de dois grafites, produzidos por biólogos, que adornavam a parede externa de um bar em Uberlândia-MG. Questões sobre o corpo pós-humano e a dimensão do amor são levantadas tendo como objeto o grafite de um robô com um coração vermelho suspenso e pássaros pousados em seus ombros e cabeça. O outro grafite é um conglomerado de fetos conectados a um dispositivo, o que remete a discussões sobre a geração de corpos com vida inteligente em laboratório. Juntamente com a produção de outros artistas e reflexões amparadas em conceitos de Bakhtin e Bauman, alguns questionamentos são tensionados no que tange a biologia que perpassa essas intervenções urbanas.
\end{abstract}

Palavras-Chave: Grafite; Arte; Vida; Corpo biônico.

\begin{abstract}
This text brings provocations from the photographs of two graffiti, produced by biologists, that decorated the external wall of a pub in Uberlândia-MG, Brazil. Questions about the post-human body and the dimension of love are raised with the object of the graphite of a robot with a red heart suspended and birds perched on its shoulders and head. The other graphite is a conglomerate of fetuses connected to a device, which refers to discussions about the generation of bodies with intelligent life in the laboratory. Along with the production of other artists and reflections based on Bauman and Bakhtin's concepts, some questions are posed regarding the biology that permeates these urban interventions.
\end{abstract}

Keywords: Graphite; Art; Life; Bionic body

\section{Resumen}

Este texto trae provocaciones del registro fotográfico de dos grafitis, realizados por biólogos, que quemaron la pared exterior de un bar en Uberlândia-MG. Las preguntas sobre el cuerpo poshumano y la dimensión del amor se plantean con el objeto del grafiti de un robot con un corazón rojo suspendido y pájaros posados sobre sus hombros y cabeza. El otro grafito es un conglomerado de fetos conectados a un dispositivo, lo que lleva a discusiones sobre la generación de cuerpos con vida inteligente en el laboratorio. Junto con la producción de otros artistas y reflexiones sustentadas en conceptos de Bakhtin y Bauman, se tensan algunas preguntas sobre la biología que impregna estas intervenciones urbanas.

Palabras Clave: Grafito; Arte; Vida; Cuerpo biónico.

${ }^{1}$ Doutora em Educação - Universidade Estadual de Campinas (UNICAMP) Campinas, SP - Brasil Professora Associada no Instituto de Biologia - Universidade Federal de Uberlândia (UFU) - Uberlândia, MG Brasil. E-mail: danielafrancocarvalho@gmail.com 


\section{Rua universidade}

Era uma tarde qualquer.

Vinte e cinco estudantes. Uma disciplina: Ciências e Mídias. Duas professoras. Uma cidade. Uma rua. Um bar. Grafites nas paredes externas. Artistas grafiteiros ${ }^{2}$. Biólogos. Infinitas ruas. Diversas cidades tensionadas em bares. E diálogos sobre as intervenções.

Como nascem os grafites? Onde são gestados? Quais misturas acontecem entre a biologia e a arte na composição criativa? Como colorir muros, bares, cidades com tintas mergulhadas em borbulhas de conteúdo biológico?

A expressão artística envolvendo o orgânico.A bióloga artista. O biólogo artista. O grafite vivo. O muro falante. Em silêncios. Em provocações. Em pausas. Em vibrações. Em vácuos. Mutante. Multi. Tudo.

Processos narrativos a partir de dois grafites. Em uma relação dialógica com o objeto de estudo na mesma proporção de uma dialética entre narrativa e experiência (CUNHA, 1997, p. 187 e 188) para que a partir dessa sensibilização pudessem ser produzidos textos de campo.

"São esses artefatos, coletados em nossas vidas, que fornecem uma fonte rica de memórias. Observar esses documentos em um contexto de pesquisa narrativa constitui algo que se pode chamar de uma arqueologia da memória e do significado" (CLANDININ e CONNELLY, 2011, p. 158).

Os textos de campo compõem esse trabalho tendo as imagens dos grafites como fonte viva de significados no bar sala de aula. Na rua universidade. Na cidade enciclopédia.

\section{Biônico}

Visão sem olhos. Para além do presente. Possibilidades de enxergar na escuridão³ .

Sendo o que não se pode mais ser. Em constante conflito.

O biônico. Meio máquina. Meio homem. Meio lata.

Em processos de passarinhização. Alavancando energias outras. Emoções. Emudecimentos.

Alimentando-se de poesia. Bicando as palavras de Manoel de Barros.

\footnotetext{
2 @geraldognomo; @flavesss

${ }^{3}$ Inspirado em Agamben - "Ser contemporâneo é antes de tudo, uma questão de coragem: porque significa ser capaz não apenas de manter o olhar no escuro da época, mas também de perceber nesse escuro uma luz que, dirigida para nós, se distancia infinitamente de nós. Ou ainda: ser pontual num compromisso ao qual se pode apenas faltar" (AGAMBEN, 2009, p. 65).
} 
DOI: http://doi.org/10.46667/renbio.v14i2.575

Figura 1: Grafite Biônico

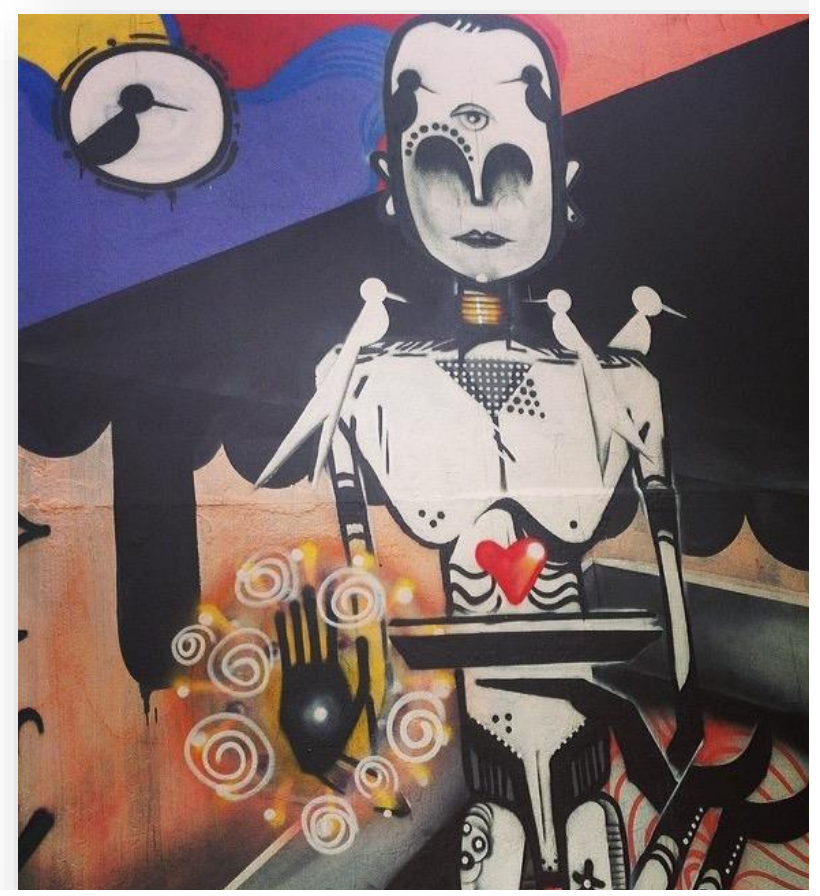

Fonte: Acervo pessoal da autora

O homem de lata é um iniciado em abrolhos e usa desvio de pássaro nos olhos ${ }^{4}$

O Homem de Lata contou a história de sua vida à Dorothy, ao Espantalho e ao Totó. Era um lenhador e gostaria de se casar com uma moça, mas a Bruxa Má do Leste fez um feitiço em seu machado que acabou cortando todas as partes de seu corpo, que foram substituídas por lata, por um latoeiro. Assim, ficou sem cérebro e sem coração. Disse que quando estava apaixonado, era o homem mais feliz do mundo, mas que ninguém pode amar se não tiver um coração.

${ }^{4}$ O Homem de Lata de Manoel de Barros (2010, p. 21-28). 
DOI: http://doi.org/10.46667/renbio.v14i2.575

"Vocês certamente salvaram a minha vida.

Como vieram parar aqui?"

"Estamos a caminho da Cidade das Esmeraldas para ver o grande

$O z$ " respondeu Dorothy.

"E por que vocês querem ver Oz?"

"Quero que ele me mande de volta para o Kansas; e o Espantalho quer que ele arranje um cérebro para a sua cabeça" respondeu a menina.

O Homem de Lata pensou por alguns instantes e disse: "você acha que o $\mathrm{Oz}$ pode me dar um coração?"

"Ora, imagino que sim. Deve ser tão fácil quanto arranjar um cérebro para o Espantalho", falou a menina 5 .

O coração

$<3$

Símbolo do que nos faz humanos.

Imortalizado em melodias, poemas, romances. Músculo estriado cardíaco. Miócitos unidos por discos intercalares. Conexão elétrica. Onda rítmica de contração celular. Em pulsos. Tum tum. Tum tum.

Os significados do homem pós-humano foram determinados sobremaneira pelos resultados e promessas da ciência e da tecnologia, sem os quais o ciborgue $^{6}$ não seria sequer inteligível. O coração é um dos objetos mais emblemáticos - tanto pela sua importância fisiológica como pelo seu valor simbólico - dos esforços científicos em superar os limites do homem com máquinas (KIM, 2004, p. 210).

Desejos de ser lata. Imortais. De romper barreiras do limite fisiológico do corpo biológico. Mas sendo humanos. Com o olhar sensível para o mundo. De encantamento. Deleite. Que permita sensações de frio na barriga. Talvez por isso o coração no estômago?

Na medida em que a máquina torna-se, de fato, a unidade de medida do homem, uma nova postura estética do corpo toma forma frente à valorização da performance: o que é belo está, cada vez mais, relacionado com o desempenho desejado (...). Na perspectiva da "estética" da performance, as máquinas de musculação, os programas planejados de modelagem muscular, as próteses estéticas, as técnicas cirúrgicas de lipoaspiração, a toxina botulínica (Botox), os anabolizantes e os complementos alimentares são apenas meios que a tecnologia disponibiliza para se atingir a imagem do corpo de alto desempenho, a imagem na direção do corpo pós-humano (KIM, 2004, p. 211-212).

\footnotetext{
5 Trecho do diálogo entre o Homem de Lata e Dorothy, no livro "O Mágico de Oz" (BAUM, 2013, p. 98-99).

${ }^{6}$ Termo oriundo de cyborg (cybernetics organism - organismo cibernético).
} 
DOI: http://doi.org/10.46667/renbio.v14i2.575

O corpo pós-humano grafitado no muro do bar. Há quem não tenha reparado no coração. Na disposição anatômica reinventada no humano pós-tecnológico.

Nos passarinhos empoleirados no homem poste.

Na bandeja laptop acoplada como prótese.

Que pulsa. Irradia. Clama.

Por des-ritmias.

Por amor.

Preciso transfundir seu sangue Pro meu coração, que é tão vagabundo

Me deixa te trazer num dengo

Pra num cafuné fazer os meus apelos

Me deixa te trazer num dengo

Pra num cafuné fazer os meus apelos

Eu quero ser exorcizado

Pela água benta desse olhar infindo

Que bom é ser fotografado

Mas pelas retinas desses olhos lindos

Me deixe hipnotizado pra acabar de vez Com essa disritmia

O artista croata Lonac ${ }^{8}$ afirma ser um contador de histórias em muros - storytelling walls. Em uma de suas produções, à mão livre e que ganhou animação em GIF, um coração gigantesco pulsa, alimentado por tubulações avermelhadas.

A obra é intitulada de "HeArtbeats", um trocadilho sobre ouvir as batidas da arte. $\mathrm{Na}$ parede. Num edifício abandonado. Onde não há pessoas. Sozinho. Sem gente. Bombeando vida no vazio.

Haverá homens sem coração e corações sem homens?

Segundo Araújo (2015), Bakhtin nos ensina que o amor é um ato desinteressado pois o objeto ao qual se destina o amor, se transforma pelo ato do olhar, e assim, o olhar amoroso modifica a intenção e o sentido do olhar.

$\mathrm{O}$ desamor e a indiferença nunca geram forças suficientes para nos deter e nos demorarmos sobre o objeto, de modo que fique fixado e esculpido cada mínimo detalhe e cada particularidade sua. Somente o amor pode ser esteticamente produtivo, somente em correlação com quem se ama é possível a plenitude da diversidade (BAKHTIN, 2010, p. 129).

Poderá a indiferença das máquinas nos aproximar uns dos outros? Como vivenciar a plenitude da vida sem essa demora? Homem-lata-passarinho. Fugitivo.

\footnotetext{
${ }^{7}$ https://www.letras.mus.br/martinho-da-vila/47310/

8 @lonacpot
} 
DOI: http://doi.org/10.46667/renbio.v14i2.575

Na conversa, no bar, com o artista e a artista biologizados pela Universidade, o questionamento de como surgiu a ideia do outro grafite montou uma órbita elíptica sobre os entrevistados. A pergunta era revisitada a todo instante. Necessidades de respostas sobre o casamento da arte e da biologia.

Num dado momento, ouvimos: foi uma superação. A criação foi se dando enquanto era composta. Em ação. Em dupla. Em parceria.

Para Bakhtin (2011, p. 183), a obra não se decompõe em uma série de elementos puramente estéticos, composicionais pois "o todo artístico é uma superação, de algum modo semântico necessário, do todo da vida possível vitalmente significativa”.

Novas possibilidades nas ruas. Nas cidades. Nas intervenções urbanas. Novos olhares artísticos que dependem do outro para serem compostos. Para se tornarem arte. Novas formas de se estar no mundo. De expressão.

Nessas práticas de arte que se estabelecem com as comunidades independentemente de sua constituição e natureza - se instaura um processo de diálogo em que todos falam para serem ouvidos, ao contrário das práticas tradicionais da arte, fundada nos princípios de especialização e originalidade do artista (...). Nessas práticas dialógicas de arte, por outro lado, o artista funciona como mediador e estimulador para que outros - em geral não artistas - se apropriem dos canais da arte para sua própria expressão (OLIVEIRA, 2009, p. 316-317).

Quanto da obra é, para nós, também produção? Quanto das nossas emoções, pulsantes, vibram no grafite? Reverberam para além do cimento, da tinta, do pincel?

Só ao término de uma contemplação artística, isto é, quando o autor [artista] deixa de guiar ativamente a nossa visão, é que objetivamos o nosso ativismo (BAKHTIN, 2011, p. 191).

Poderíamos, ao deixar de sermos guiados, perceber a imagem, a obra, a produção como construções dialéticas?

Não é que o passado lança sua luz sobre o presente ou que o presente lança sua luz sobre o passado: mas a imagem é aquilo em que o ocorrido encontra o agora num lampejo, formando uma constelação. Em outras palavras: a imagem é a dialética na imobilidade. Pois, enquanto a relação do presente com o passado é puramente temporal e contínua, a relação do ocorrido com o agora é dialética - não é uma progressão, e sim uma imagem, que salta. Somente as imagens dialéticas são imagens autênticas (isto é: não-arcaicas),e o lugar onde as encontramos é a linguagem (BENJAMIN, 2006, p. 504). 
DOI: http://doi.org/10.46667/renbio.v14i2.575

E sendo dialética... ilimitada, mutável. Em constituição mútua e ativa no processo de interação entre o sujeito que experiência, o autor da obra e todas as vozes que constituem os discursos que estão postos.

Não existe a primeira nem a última palavra, e não há limites para o contexto dialógico (este se estende ao passado sem limites e ao futuro sem limites). Nem os sentidos do passado, isto é, nascidos do diálogo dos séculos passados, podem jamais ser estáveis (concluídos, acabados de uma vez por todas): eles sempre irão mudar (renovando-se) no processo de desenvolvimento subsequente, futuro do diálogo. Em qualquer momento do desenvolvimento do diálogo existem massas imensas e ilimitadas de sentidos esquecidos, mas em determinados momentos do sucessivo desenvolvimento do diálogo, em seu curso, tais sentidos serão relembrados em forma renovada (BAKHTIN, 2003, p. 410).

Tornamos-nos ativistas pelo olhar do artista? Pelas mãos do outro passamos, em diálogo, a pulverizar novos entendimentos? Aquilo que nos toma de surpresa. O inesperado. Que nos faz pensar diferente a partir do novo.

Os artistas na pós-modernidade (...) parecem ter abandonado por completo as práticas comprometidas com noções de pureza e autonomia, e tem produzido seus projetos e obras em contato direto com o mundo, sem medo das contaminações, ao contrário, ávidos por esses contágios mundanos, sem medo de encontrar esse mundo onde ele é mundo, sem medo de desvelar seu espanto e perplexidade diante da beleza do mundo (OLIVEIRA, 2009, p. 320).

Estamos nós também cada vez mais ávidos por esses contágios? Contaminamo-nos uns aos outros através dos barulhos da arte que não escutamos nas paredes mas que ecoam em nós? De fora para dentro e de dentro para fora? Subvertendo dinâmicas estáticas de se ver e estar nas cidades?

Bares escolas. Muros professores. Biólogos artistas.

Homens e mulheres em perplexidade. Em belezas. 


\section{Desplacentados}

Máquinas gestacionais. Fetos. Animais-humanos. Desplacentados. Em brotamento. Observados em transe. Emergidos da terra. Do concreto. Do mundo. Fluidificados. Nutridos. Em vermelho e azul. Venoso. Arterial. Hipnotizados. Acoplados. Univitelinos. Mesomorfos. Clonados. Órfãos.

Figura 2: Desplacentados

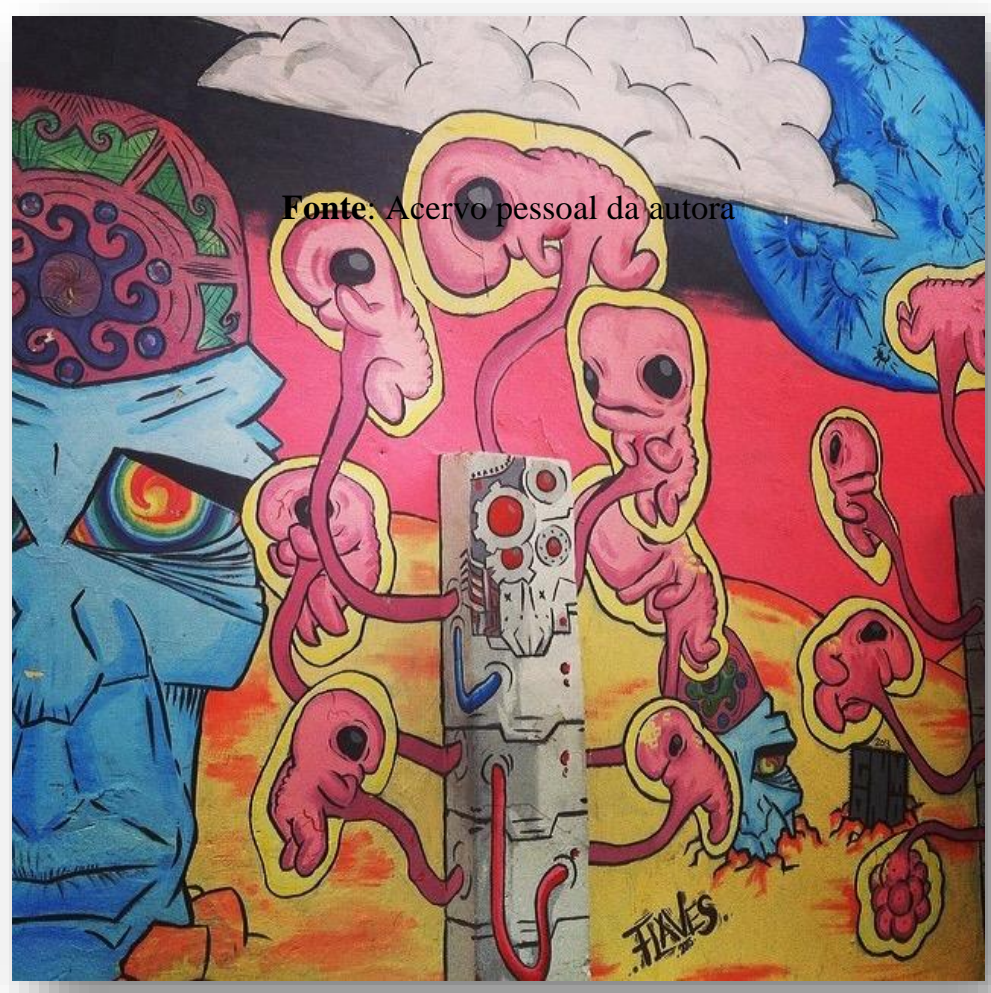

Geração de corpos com vida inteligente em laboratório. Drive-thru. Substituição de entes queridos por outros. Iguais. Não de lata. Com coração. Em carne e osso.

Uma realidade distante? Estampada apenas no grafite da @flavesss e do @ geraldognomo?

Produção em massa para atender aos desejos de não sofrermos mais?

O episódio "Volte $\log o$ "" da série britânica Black Mirror polemiza essa situação, pois ao perder o esposo em um acidente de carro, uma jovem designer gráfica encomenda em uma empresa, um clone do marido morto, alimentado com dados extraídos das redes sociais, e-

\footnotetext{
9 Original: "Be right back”. Para saber mais sobre esse episódio e considerações sobre o "homem pós-orgânico", veja o texto de Barbosa e colaboradores (2015).
} 
DOI: http://doi.org/10.46667/renbio.v14i2.575

mails, fotografias e histórias pessoais. Com o passar do tempo, ela percebe que o que tinha em sua casa não era o amado ressuscitado, mas um outro ser, configurado por matéria orgânica e dados digitais, que não correspondia às suas expectativas.

Pura ficção.

É?

Bem, ao toque dos dedos e dos números de um cartão de crédito é possível encomendar ultrassonografias, lâminas histológicas, fotomicrografias, fotografias e ilustrações diversas de fetos humanos pela internet ${ }^{10}$.

Corpos sem nome. Sem história. Sem vida. Fetos abortados. Gerados em barrigas que não sabemos de quem são. E que podem ser comprados a partir de vinte dólares. Estampados em papel cartão, acrílico, metal. Você escolhe: quadro, com ou sem moldura, cartão postal ou almofadas.

O tempo de desenvolvimento fetal também pode ser negociado. Dez semanas? Onze? No nascimento? O que vai ser?

O desvanecimento das habilidades de sociabilidade é reforçado e acelerado pela tendência, inspirada no estilo de vida consumista dominante, a tratar os outros seres humanos como objetos de consumo e julgá-los, segundo o padrão desses objetos, pelo volume de prazer que provavelmente oferecem e em termos de seu "valor monetário". Na melhor das hipóteses, os outros são avaliados como companheiros na atividade essencialmente solitária do consumo, parceiros nas alegrias do consumo, cujas presença e participação ativa podem intensificar esses prazeres. Nesse processo, os valores intrínsecos dos outros como seres humanos singulares (e assim também a preocupação com eles por si mesmos, e por essa singularidade) estão quase desaparecendo de vista. A solidariedade humana é a primeira baixa causada pelo triunfo do mercado consumidor (BAUMAN, 2004, p. 97-98).

Quem são esses bebês que agora enfeitam a sala? Podem amenizar sofrimento de perdas? Substituir alguém que não se tem mais? Desejos de maternidade volatilizados.

O artista nova-iorquino David Parker da Science Photo Library ${ }^{11}$, produz fotografias coloridas a partir de radiografias de fetos com nove meses de gestação, no abdômen materno.

\footnotetext{
${ }^{10}$ A empresa norte-americana fineartamerica.com, localizada em Nova York, comercializa pela internet produtos artísticos diversos, que podem ser localizados por temas e palavras-chave. Um dos temas disponíveis é "fetus" (fetos).

${ }^{11}$ https://www.sciencephoto.com/contributor/dpa 
DOI: http://doi.org/10.46667/renbio.v14i2.575

Cabeças. Pélvis. Coluna vertebral. Gêmeos. Mãe. Filho único. Ossos. Massa. Modelos. Poses para nascimentos comuns. Clandestinidades. Arte a partir do biológico. Cientificidades. Ilusões reais. Coloridos estáticos do que foi. Mais um.

A artista alemã Irmgard Schoendorf Welch ${ }^{12}$ tem uma série de pinturas digitais que aborda o universo dos fetos e o olhar feminino para eles, intitulada "Pensando sobre sua criança não nascida...".

Sendo outra mulher a partir da tragédia.

Em transvisibilidades com a cidade. Com o quarto. Com os detalhes que lembram o que não se materializou para além útero. $\mathrm{Na}$ dimensão única de ser mãe sem filho. Em lembranças. Para sempre.

Faraco (2003, p. 83), em suas leituras de Bakhtin, diz que o sujeito é social de ponta a ponta (a origem do alimento e da lógica da consciência é externa à consciência) e singular de ponta a ponta (os modos como cada consciência responde às suas condições objetivas são sempre singulares, porque cada um é um evento único do Ser).

Nossa singularidade de ponta a ponta esvaída em comércio eletrônico. As dores de mães de natimortos substituídas por embrulhos em plástico bolham. A vida - evento único emoldurada na parede.

Na liquidez do cotidiano.

Pensar com Bauman sobre essa comercialização de vidas, sobre a mercantilização das relações humanas, envolve tensionamentos em relação ao sujeito singular.

[...] que o destino final de toda mercadoria colocada à venda é ser consumida por compradores; que os compradores desejarão obter mercadorias para consumo se, e apenas se, consumi-las por algo que prometa satisfazer seus desejos; que o preço que o potencial consumidor em busca de satisfação está preparado para pagar pelas mercadorias em oferta dependerá da credibilidade dessa promessa e da intensidade desses desejos (BAUMAN, 2008, p. 18).

Desejos frustrados alimentam a demanda de consumo e mantém a economia em movimento. Uma mulher que abortou. Um filho não nascido. À mãe é ofertada uma gama de itens consumíveis em substituição ao bebê. Filhos de outras mães. Pedaços de corpos fetais materializados em produções artísticas.

$12 @$ irmgardschoendorfwelch 
DOI: http://doi.org/10.46667/renbio.v14i2.575

A singularidade do filho, cuja existência única não pode ser ressuscitada, é pulverizada em objetos acessíveis em dólares. O desejo à maternidade condensado em moeda de troca. Se há mercado para a venda desses itens, cujos valores da vida humana são extirpados, há consumidores. Consumidores-mercadoria.

A vida humana embrionária como fetiche.

Em uma sociedade de mercado, o fetiche da mercadoria é um dos principais organizadores do laço social. Mas a diferença que o fetiche da mercadoria apaga não é (exclusivamente) sexual; ele apaga a diferença entre o capitalista e o trabalhador, entre quem vende e quem compra força de trabalho, entre quem lucra e quem cede mais-valia. A mercadoria que brilha como pura positividade, como máxima expressão de riqueza, é um fetiche em função de sua capacidade de ocultar a miséria, a exploração e a morte investidas em seu corpo. Nas sociedades de consumo, o fetichismo é a normalidade (KEHL, 2004, p.8).

Pode a arte nos provocar a buscar frestas na densidade complexa dos dias que vivemos para sairmos do modus operandi consumista?

A arte do americano Bobby Zeik ${ }^{13}$ vem de ensaios na rua e atualmente mistura métodos tradicionais com efeitos digitais. Em uma produção de 2012, intitulada Philly Rapture, elaborada integralmente com spray sem tratamento posterior, há muitos prédios com janelas iluminadas em um fundo avermelhado, em chamas. Crânios alados assemelham-se a morcegos em vôo. Uma mão gigantesca com unhas proeminentes desce do céu. Um monstro azulado aparece ao fundo. Fitas róseas saem de um feto humano verde-limão flutuante e envolvem os edifícios .

A vida fetal alimentada pela cidade.

Em justaposição com a energia que percorre os prédios. Em meio aos nossos medos urbanos. Paranóias. Fobias. Pavores. Que nos atormentam por arranha-céus e submundos do metrô. Pequenos bebês indefesos dentro de nós. Cordões umbilicais que absorvem frestas.Interligações com o outro que nos faz ser o que somos.

Biologias que perpassam intervenções no mundo para nos tocar. Muito mais que sangue, músculos, ossos e células. Muito mais que chips, memória eletrônica e rede cibernética.

${ }^{13}$ www.bobbyzeikart.com 
Muito mais.

Para nos fazer humanos.

Únicos.

\section{Referências}

AGAMBEN, Giorgio. O que é contemporâneo? E outros ensaios. Tradução Vinícius Nicastro Honesko. Chapeço: Argos, 2009.

ARAÚJO, Angélica Duarte da Silva. Os vários encontros de amor. In: Grupo de Estudos Bakhtinianos ATOS/UFF. Palavras próprias-alheias: ela. Vida, arte, alteriadade. São Carlos: Pedro \& João Editores, 2015, p. 69.

BAKHTIN, Michael. Para uma filosofia do ato responsável. São Carlos: Pedro \& João Editores, 2010.

BAKHTIN, Michael. Estética da criação verbal. São Paulo: Martins Fontes: 2003.

BARBOSA, Cléber Pimentel; MORAIS, Leonardo David de; RIBEIRO, Ludmila Ameno. "Homem Pós-Orgânico" ou "Frankenstein Pós-Moderno"? Um caso de amor \& morte em "Be Right Back", da Série Black Mirror. E-scrita, v.6, n. 1, p. 271-281, 2015.

BARROS, Manoel de. Gramática expositiva do chão. São Paulo: Leya, 2010.

BAUMAN, Zigmunt. Vida para consumo: a transformação das pessoas em mercadoria. Rio de Janeiro: Zahar Ed., 2008.

BAUMAN, Zygmunt. Amor líquido. Sobre a fragilidade dos laços humanos. Rio de Janeiro: Zahar Ed., 2004.

BENJAMIN, Walter. Passagens. Belo Horizonte. Editora UFMG: São Paulo:Imprensa Oficial do Estado de São Paulo, 2006.

CLANDININ, Jean; CONNELLY, Michael. Narrative inquiry: experience and story in qualitative research. Translation: Narrative Inquiry Group and Teacher Education ILEEI/UFU. Uberlândia: EDUFU, 2011.

CUNHA, Maria Isabel da. Conta-me agora!: as narrativas como alternativas pedagógicas na pesquisa e no ensino. Rev. Fac. Educ. [online]. 1997, vol.23, n.1-2 [cited 2019-05-28], pp.-. Disponível em: https://www.scielo.br/scielo.php?script=sci_arttext\&pid=S010225551997000100010\&lng=en\&nrm=iso Acesso em: 18 de março de 2021.

FARACO, Carlos Alberto. Linguagem e diálogo: as ideias linguísticas do Círculo de Bakhtin. Curitiba, Paraná: Criar, 2003.

KEHL, Maria Rita. A publicidade e o mestre do gozo. Comunicação, Mídia e Consumo, v. 1, n.2, p. 1-15, 2004. 
KIM, Joon Ho. Cibernética, ciborgues e ciberespaço: notas sobre as origens da cibernética e sua reinvenção cultural. Horizonte antropológico, Porto Alegre, v. 10, n. 21, p. 199-219, 2004.

OLIVEIRA, Luiz Sérgio de. A perplexidade do autor diante da beleza do mundo. In: Walter Benjamim: arte e experiência. Organização Luiz Sérgio de Oliveira, Martha D'Angelo. Rio de Janeiro: Nau; Niterói: EdUFF, 2009.

Recebido em março de 2021. Aprovado em setembro de 2021.

Revisão gramatical realizada por: Beto Oliveira

E-mail: betooliveirafoto@gmail.com 